\title{
HARMONIC LOAD MODELING: A CASE STUDY OF 33 KV ABUJA STEEL MILL FEEDER
}

\author{
M. N. Nwohu' ${ }^{1}$, B. Tanko ${ }^{2}$, H. Ohize ${ }^{3}$, A. A. Sadiq ${ }^{4}$ and A. A. Usman ${ }^{5}$ \\ 1,3,4,5, Electrical/Electronic Engr. Department, Fed. Univ. of Technology, Minna, Niger State, NigERia \\ 2, Monitoring and Evaluation DePartment, TRANSmission Company of Nigeria, ABUja, NigERIA

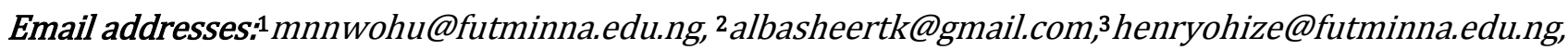 \\ 4ahmad.abubakar@futminna.edu.ng,5usman.abraham@futminna.edu.ng
}

\begin{abstract}
An in-depth study of the harmonic orders inherent in a power system network is required before mitigation techniques are adopted. This paper studied the harmonic orders of the $33 \mathrm{kV}$ Abuja Steel Feeder modeled as a harmonic source using measured data. Readings of $\mathrm{kW}, \mathrm{kVar}, \mathrm{kV}$ and $\mathrm{Hz}$ were obtained using power quality analyzer (PQube) to identify the trend and the harmonic unbalance on the feeder. Electrical Transient Analyzer Program (ETAP) software package was deployed to perform Discrete Fast Transform (DFT) while the input parameters were the resultant relative amplitudes and phase angles for both the current and voltage source models. The current source model spectrum of the feeder under study revealed that the $11^{\text {th }}$ and $13^{\text {th }}$ harmonic orders have the highest percentage of amplitude relative to the fundamental compared to the other harmonics. On the other hand, the voltage source model spectrum showed that the $14^{\text {th }}, 15^{\text {th }}, 16^{\text {th }}, 17^{\text {th }}, 32^{\text {th }}, 33^{\text {rd }}$ and $34^{\text {th }}$ harmonic orders have higher percentage of

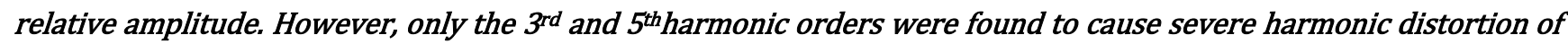
voltage and current after harmonic analysis and frequency scan were performed on the ETAP platform.
\end{abstract}

\section{Keywords: Harmonic order; Power quality; Transmission grid; ETAP; Tuned filters}

\section{INTRODUCTION}

The recent deregulation of Nigerian power sector has led to an increased concern on power quality among all the stakeholders. Power quality has been severely affected by harmonic distortion of current and voltage with its attendant unpleasant consequences. This is attributable to the ever increasing use of power electronic devices and equipment such as variable speed drives, uninterruptible power supplies (UPS) and static power converters as well as large number of industrial loads connected to its transmission infrastructure and other non-linear loads or devices such as arc furnaces, saturated transformers, fluorescent lightings and cyclo-converters [1, 2]. Data from the National Control Centre (NCC), Oshogbo revealed a staggering frequency profile and high harmonic distortion of both voltage and current. Components other than the fundamental voltage and current were found to exist in the distorted waveform as integer multiples of the fundamental frequency. The effects of these harmonic distortion on the Nigerian power grid are experienced in all network buses and are partly responsible for the high system forced outages, false trip on circuit breakers, corruption of metering calibration and data, poor frequency profile and high transmission losses. Data obtained from the Monitoring and Evaluation Sub-sectors of the Transmission Company of Nigeria (TCN) revealed a high rate of transmission loss factor that hovers between $7.05 \%$ and $14 \%$ monthly. Other likely effects that are sometimes attributable to high harmonic current include loss of power transformers, earthing transformers and instrument transformers due to saturation, frequent total and partial system collapses due to voltage swells or dips, damage to capacitor banks and loss of direct current (DC) system in transmission substations due to battery charger failure. Interestingly, research in this area has received little or no attention from the Nigerian power system planning engineers, the academics and other stakeholders in the industry. The phenomenon has been allowed to overcome itself by natural immunity, system density and the interconnected nature of the transmission grid [3].

Harmonic study and mitigation on the Nigerian power network has not been properly appraised both at transmission and distribution level. While line reactors and under-frequency relays exist in the transmission 
network to address other power quality challenges, no harmonic filter or Flexible Alternating Current Transmission System (FACTS) devices for the purpose of addressing power quality and harmonic distortion on the power network has been implemented or installed as the Transmission Company of Nigeria network asset data revealed. This work is particularly significant to Nigeria power system operators where only voltage and frequency are being properly monitored and controlled.

Harmonic load modeling of some Nigerian steel plants feeders using idealized models have been simulated and documented in research and development articles [4][5]. However, modeling of these loads using measured data obtained from power quality analysers on the Nigerian grid network appears very un-common. Therefore, this study attempts to blaze the trail on this all important power quality issue in the Nigerian grid network with $33 \mathrm{kV}$ Abuja Steel feeder as case study.

\section{REVIEW OF HARMONIC MODELING IN POWER SYSTEM NETWORK}

Harmonic modeling is a mathematical way of predicting harmonic distortion levels and potential resonance on an electrical network based on available system data [6]. The steps required for making harmonics study based on industrial research and experience involved obtaining the single line diagrams of the network, highlighting the point of common coupling, identification of harmonic sources and/or carrying out harmonic measurements, modeling the network components using a simulation software like ETAP and comparing results obtained to national standards [7]. Power quality meters may be installed on a number of buses having large non-linear load in order to determine the level of unbalance. The locations of these measurements should be the Point of Common Coupling (PCC) which is the customer-utility interface. A minimum measurement period of one week is normally recommended as it provides a representative loading cycle for most industrial and commercial loads [8].To obtain reliable harmonic model of any network, all components of the network must be precisely modeled. In order to carry out a comprehensive harmonic modeling and simulation of the Abuja Steel feeder, two categories of literatures were identified and reviewed so as to establish the gaps and come up with a more reliable result. The first group centres on harmonics modeling using traditional method otherwise called the ideal current source models [9]-[16]. Khaled, et al. [9] and Ali [10] deployed the use of idealized models. An important reference is Khaled, et al. [9] wherein harmonic model of the load under study was selected from the ETAP library as a harmonic current source of the IEEE-12-pulse type 2. Similarly, Ali [10]investigated the propagation of harmonic current in a power network using hypothetic model that injects harmonic current of $3^{\text {rd }}, 5^{\text {th }}, 7^{\text {th }}$ and $9^{\text {th }}$ orders developed on Alternative Transient Program (ATP-Draw) software. A major drawback of these idealized models is that they do not give a true reflection of the network's harmonics penetration and propagation on real time. Attempts were made in the works of [11]-[13] to utilize field measured data to model harmonic generating loads. Various simulation software were used including ETAP as in Hagh et al. [11] wherein on-site harmonic current measurements were used to tune the computer based harmonic current models to match and validate the measured data. Power System Computer Aided Design/Electromagnetic Transients including DC (PSCAD/EMTDC) was deployed in Venkatesh et al. [12] to develop simulation models based on laboratory measured waveforms. A generalized model for distribution systems was successfully implemented for practical case studies using the verified simulation models for various industrial and household electrical equipment and appliances. Similarly, DigSilent/Power factory is the simulation software used in Ma et al.[13] to evaluate the future levels of harmonic distortion in a power grid based on the present harmonic current source model developed from measured data.

The second group of literature review proposed the use of equivalent circuit models to represent characteristic harmonic producing loads [14]-[16]. The Norton/ Thevenin equivalent circuit provides a reliable model for harmonic current and voltage sources in a distribution network. The contribution of the power utility equipment and customer loads to total harmonic distortion observed at the point of common coupling (PCC) can separately be evaluated using field data and analytical techniques [14]. The major challenge of the Thevenin/Norton equivalent circuit models is the determination of the impedance and other parameters of the power network. Evolutionary algorithm have been tested and verified in the estimation of Thevenin/ Norton equivalent circuit parameters without knowing the network impedance [15]. An equivalent circuit that considered the modeling of the harmonic current emission on the $\mathrm{AC}$ side of a diode bridge rectifier while evaluating the harmonic voltage contribution of the DC side of the rectifier was successfully developed [16]. The drawback of modeling only the harmonic current was successfully addressed for a more accurate harmonic analysis.

In this research work, we aimed at modeling the current and voltage harmonic content of the $33 \mathrm{kV}$ Abuja Steel Feeder using ETAP software. A two week data was obtained from power quality meter installed on the 
feeder at the point of common coupling (PCC). The ETAP Harmonic Analysis module was utilised to obtain the harmonic load model of the Abuja Steel Feeder for both harmonic current and voltage sources respectively. The Thevenin/Norton Equivalent model was selected for this research. This model involves the representation of both the utility and customer sides with Thevenin/Norton equivalent circuits. Results obtained served as bases for further harmonic analysis and mitigation on the load under study. Its effect on other power network components and loads were revealed during harmonic load flow and frequency scan.

\section{SULEJA POWER NETWORK DESCRIPTIONANDABUJA STEEL FEEDER SIMULATION}

The Suleja power network is composed of 132/33 kV transmission sub-station located in Niger State, Nigeria. The station is mesh connected to the National grid through four numbers of high voltage circuits namely Abuja-Suleja 132 kV Line I, Abuja-Suleja 132 kV Line II, Minna-Suleja $132 \mathrm{kV}$ Line I and Minna-Suleja $132 \mathrm{kV}$ Line II. While the Abuja circuits emanate from the Ketampe 330/132 kV transmission station in Abuja, Minna circuits emanate from Minna $132 \mathrm{kV}$ transmission substation(primary supply source for both stations is ShiroroHydo-electric Power station in Niger state). The Suleja 132/33 kV sub-station has three power transformers rated as follows: 7.5MVA 132/11 $\mathrm{kV}$ transformer TR1 feeding five $11 \mathrm{kV}$ feeders (Gauraka, Dikko, Minna Road, NNPC and Water Works $11 \mathrm{kV}$ feeders); 45MVA 132/33 kV transformer TR2 feeding two $33 \mathrm{kV}$ feeders (Abuja Steel and Field Base $33 \mathrm{kV}$ Feeders); and 60MVA 132/33 kV transformer TR3 feeding two $33 \mathrm{kV}$ feeders (Jere and Kantoma $33 \mathrm{kV}$ feeders).

Suleja Power Network has three 33/11 kV Injection sub-stations located at Kantoma, Jere and Field Base. Kantoma 33/ $11 \mathrm{kV}$ Injection substations have two power transformers each rated 15MVA with four $11 \mathrm{kV}$ feeders namely Dawaki, Hassan Dalhatu, RafinSanyi and Madalla; Field Base 33/11 kV injection substation has one power transformer rated 15MVA with two feeders namely Suleiman Barau and Tommy; while Jere 33/11 $\mathrm{kV}$ Injection substation has two power transformers rated 7.5 MVA feeding three feeders namely SabonLugbe, SabonDikko and Nasara $11 \mathrm{kV}$ feeders. All the other major network equipment like circuit breakers, isolators and buses were also modeled and simulated on the ETAP software package. The fourteen $11 \mathrm{kV}$ distribution feeders were modeled as aggregate loads based on load readings collected and analyzed from field data. Single Line Diagram of the Suleja Power Network modeled for this research is shown in the attached Appendix.
The Abuja Steel feeder under case study is a $33 \mathrm{kV}$ feeder supplied by the $132 / 33 \mathrm{kV}$ Suleja transmission substation, Niger State, Nigeria. It feeds the Abuja Steel plant located about $15 \mathrm{~km}$ away from the substation through a $33 \mathrm{kV}$ distribution line. The plant is composed of two induction furnaces that produce high quality steel from scrap metal with a capacity of 15 Tons each and rated $33 / 1 \mathrm{kV}$.

Power Quality Analyser (PQube) produced by Power Standard Lab was installed on the secondary side of 45MVA transformer TR2 at Suleja 132/33 kV transmission substation. This transformer supplies the $33 \mathrm{kV}$ Abuja Steel Feeder. Two weeks data was retrieved from the PQube's Secure Digital (SD) memory card for the purpose of this study. The two weeks spanned between $1^{\text {st }}$ and $16^{\text {th }}$ January, 2016. The data was further analysed using Discrete Fourier Transform (DFT) analysis capability on the ETAP software's harmonic analysis module to obtain the spectrum and waveform of the harmonic model for the Abuja steel feeder.

\section{METHODOLOGY}

Data collected from the harmonic measurement of the $33 \mathrm{kV}$ Abuja Steel plant was carefully studied. The load variation within the two weeks period was analyzed and the maximum total harmonic distortion as percentage of the fundamental voltage and current was compared for the fourteen day period. Day seven shows the highest level of total harmonic distortion of voltage (VTHD) with a peak and average of $13.1 \%$ and 5.8\% respectively. Generally, the harmonic distortions for all the days reveal a high level of distortion above tolerable limit of $2.5 \%$ as specified in Nigerian Grid code, $3.5 \%$ for IEC 61000-4-30 (2003) and 5\% for IEEE Std. 519 (1992)[17]-[19].

Therefore, the seventh day was selected for the harmonic load modelling as it provides the probable worst case scenario for the feeder. The loading of Abuja Steel feeder was found to be near maximum on this day. Furthermore, ETAP deploys Discrete Fourier Transform (DFT) technique to model the distorted waveform and spectrum of any load model under case study. PQube's harmonics data contains Amplitude, Phase Angle and Inter-harmonics Amplitude of both current and voltage captured separately on a ten minutes interval daily for the three phase lines herein referred to as Line 1 (Red Phase), Line 2 (Yellow Phase) and Line 3 (Blue Phase). These three phase amplitudes and phase angles (in degrees) were combined to produce a resultant data for the Abuja Steel line at every capture. Daily average resultant values of amplitude and phase angle were computed for each harmonic order and then selected for simulation. Amplitudes of all other harmonic order 
were presented as percentage of the peak amplitude of the fundamental which is the $1^{\text {st }}$ order harmonic referred to as H1. Although the PQube records up to the $63^{\text {rd }}$ order Harmonic, this research truncates harmonics above $40^{\text {th }}$ order since the higher order harmonics were observed to have low amplitudes.

Fourier series expresses every periodic function as given in equation $1[11]$, [14], [15]:

$$
f(t)=\frac{1}{2} a_{0}+\sum_{k=1}^{\infty}\left(a_{k} \cos 2 \pi k t+b_{k} \sin 2 \pi k t\right)
$$

$\mathrm{K}$ represents frequency of the Kth harmonics order.

Continuous Fourier transform is given by:

$$
X(F)=\int_{-\infty}^{\infty} x(t) \cdot e^{-j 2 \pi F t} d t
$$

Where $x(t)$ is a function and $e^{-j 2 \pi F t}$ is the analyzing function (sinusoid).

Discrete Fourier transform is given by:

$$
X_{K}=\sum_{n=0}^{N-1} x_{n} e^{-\frac{2 \pi K n}{N}}
$$

Where $K$ is the Kth frequency, $\mathrm{n}$ is the sampled frequency and $\mathrm{N}$ is the number of samples.

$$
\frac{k}{N} \stackrel{\Delta}{=}{ }^{\prime}, n_{=}^{\Delta} \text { tand }_{n}=\frac{2 \pi K n}{N}
$$

For harmonics analysis, $X_{K}$ will be replaced with $H_{K}$,

$$
K_{K}=h_{0} e^{-b_{0} j}+h_{1} e^{-b_{1} j}+\cdots+h_{n} e^{-b_{N 1 j}}
$$

From Euler's formula:

$$
\begin{gathered}
e^{j x}=\cos x+\sin x \\
H_{K}=h_{0}\left[\cos \left(-\mathrm{b}_{0}\right)+j \sin \left(-b_{o}\right)\right] \\
+h_{1}\left[\cos \left(-\mathrm{b}_{1}\right)+j \sin \left(-\mathrm{b}_{1}\right)\right] \\
H_{K}=A_{K}+j B_{K} \\
A_{K}=L_{K 1} \cos \theta_{K 1}+L_{K 2} \cos \theta_{K 2}+L_{k 3} \cos \theta_{k 3} \\
B_{K}=L_{K 1} \sin \theta_{K 1}+L_{K 2} \sin \theta_{K 2}+L_{k 3} \sin \theta_{k 3}
\end{gathered}
$$

$L_{K 1}, L_{K 2}, L_{K 3}$ and $\theta_{K 1}, \theta_{K 2}, \theta_{K 3}$ are the amplitudes and phase angles for Line 1 , Line 2 and Line 3 at Kth harmonic order as obtained from PQube meter respectively. The Magnitude and phase are given as:

$$
\begin{aligned}
\operatorname{Mag}_{k} & =\sqrt{A_{k}^{2}+B_{k}^{2}} \\
\theta_{K} & =\tan ^{-1} \frac{B_{K}}{A_{K}}
\end{aligned}
$$

The Thevenin/Norton Equivalent model was selected for this research as the power electronics circuits of the steel rolling mill and induction furnaces inject harmonic current to the power network. Similarly, the network contributes its own component of harmonic current to the PCC. Therefore, harmonic vector method applied here involves the representation of both the utility and customer sides with Thevenin/Norton equivalent circuits. Thevenin and Norton equivalent circuits were used to separately compute the harmonic voltage and current contributions to the PCC. The Suleja power network's reference impedance was calculated from the summation of the impedance of the power transformer supplying the Abuja Steel feeder (45MVA transformer TR2) and the network's short circuit impedance obtained from the grid data.

\section{HARMONIC LOAD MODEL OF THE ABUJA STEEL FEEDER}

The ETAP software has a robust library that allows for the building and to customize harmonics sources and store on the library's shelves. The relative amplitude and phase angle of each harmonic order from the $1^{\text {st }}$ to $40^{\text {th }}$ were the input parameters to the model. The software then performs DFT to generate the spectrum and waveform.

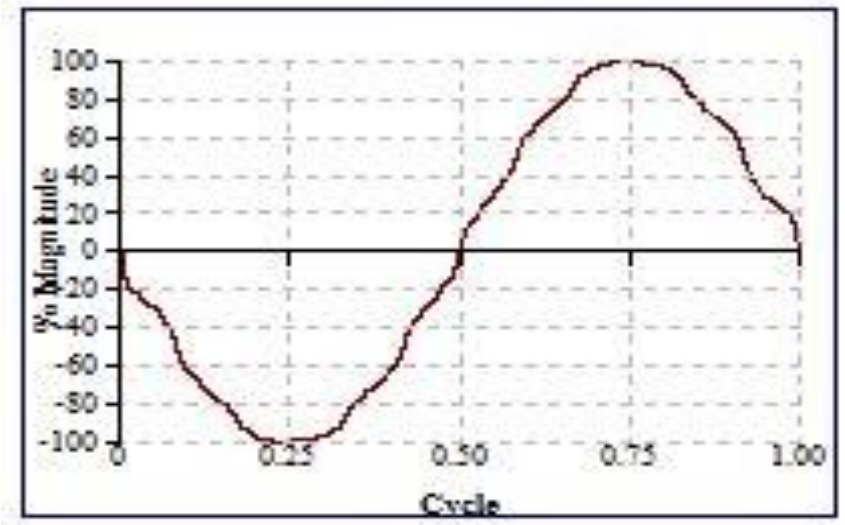

Fig. 1. Harmonics Current Source Model (Waveform) of Abuja

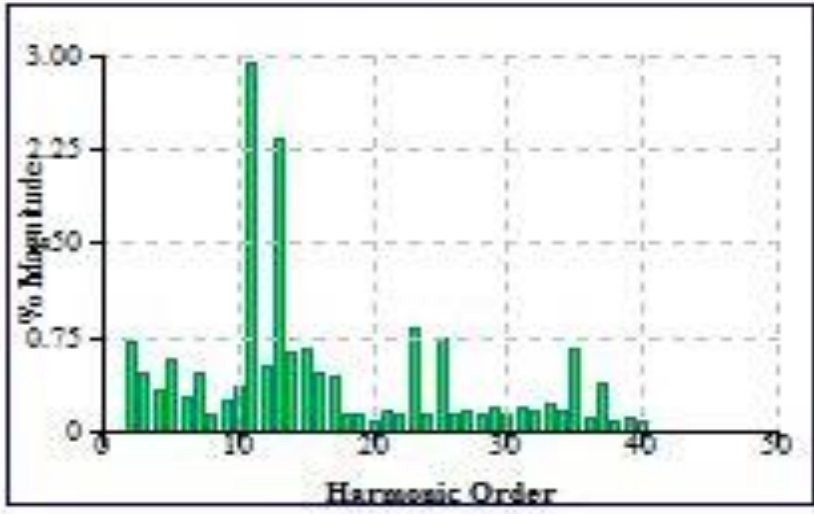

Fig. 2. Harmonics Current Source Model (Spectrum) of Abuja Steel Feeder

\subsection{Current Source Model}

The spectrum in Figure 2 reveals that $11^{\text {th }}$ order harmonics creates the highest level of distortion with a value of $3 \%$. It is closely followed by the $13^{\text {th }}$ order harmonics with $2.3 \%$. Its waveform is as shown in Figure 1. Fig. 3 and Fig. 4 depict the wave form and spectrum respectively up to $40^{\text {th }}$ harmonic order for the feeder as a current source model.

However, after harmonic analysis of the entire Suleja Distribution network with Abuja steel feeder modelled as a harmonic current source, the propagation of harmonics was observed on the various network buses, 
power transformers and lines. The harmonic current of the $5^{\text {th }}$ order was amplified from an initial value of $0.5 \%$ to about $5.76 \%$. Generally, only the $3^{\text {rd }}$ and $5^{\text {th }}$ order harmonics resulted in the harmonic distortion experienced on the entire network. A result of the Individual harmonic distortion of voltage (VIHD) is presented on Table 1.

Table 1. VIHD showing the penetration of $3^{\text {rd }}$ and $5^{\text {th }}$ harmonics on the network using the current source model

\begin{tabular}{lcc}
\hline Bus ID & VIHD & Harmonic Order \\
\hline Field Base 11kV & 15.95 & 3.00 \\
Jere 11kV Bus & 14.15 & 3.00 \\
Jere 11kV Bus 1 & 13.95 & 3.00 \\
Suleja Main Bus & 13.34 & 3.00 \\
Suleja Transfer Bus & 13.34 & 3.00 \\
Bus4 & 5.12 & 3.00 \\
Abuja Steel Bus1 & 5.76 & 5.00 \\
Feld Base 11kV & 2.94 & 5.00 \\
FieldBase 33kV Inj S/S & 4.74 & 5.00 \\
Jere 11kV Bus 1 & 2.51 & 5.00 \\
Jere 33kV Inj. S/S & 6.13 & 5.00 \\
Kantoma 11kV Bus 1 & 7.38 & 5.00 \\
Kantoma 11kV Bus 2 & 7.38 & 5.00 \\
Kantoma 33kV Inj. S/S & 7.53 & 5.00 \\
Suleja 11kV Bus & 6.37 & 5.00 \\
Suleja 33kV Bus 1 & 7.58 & 5.00 \\
Suleja 33kV Bus3 & 5.82 & 5.00 \\
Suleja Main Bus & 2.81 & 5.00 \\
Suleja Transfer Bus & 2.81 & 5.00 \\
\hline
\end{tabular}

\subsection{Voltage Source Model}

Similarly, the harmonic voltage source model of the feeder was generated using resultant three phase amplitude in $\mathrm{kV}$ and phase angles obtained from analyzing the power quality data. A careful perusal of the spectrum shows that the $35^{\text {th }}$ order harmonics generates the highest level of distortion with a magnitude of $2 \%$. Other harmonic orders with high magnitude of relative amplitude are $11^{\text {th }}, 13^{\text {th }}, 23^{\text {rd }}, 25^{\text {th }}$ and 37th. Fig. 5 and Fig. 6 show the waveform and spectrum of the voltage source model up to $40^{\text {th }}$ order of harmonic for the Abuja Steel feeder before harmonic analysis and frequency scan on ETAP platform was performed. Analysis of the individual harmonic distortion of voltage for the voltage source model as presented on Table 2 reflects the same trend as that of the current source model whereon only the $3^{\text {rd }}$ and $5^{\text {th }}$ order harmonics becomes of utmost concern.

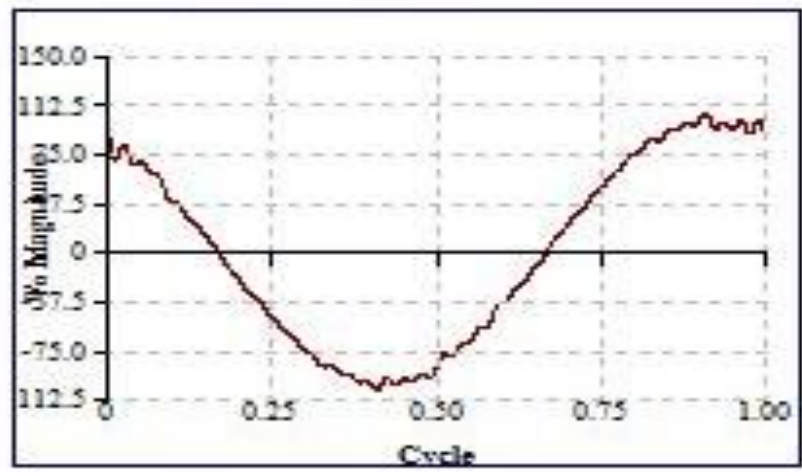

Fig. 3. Harmonics Voltage Source Model(Waveform) of Abuja Steel Feeder

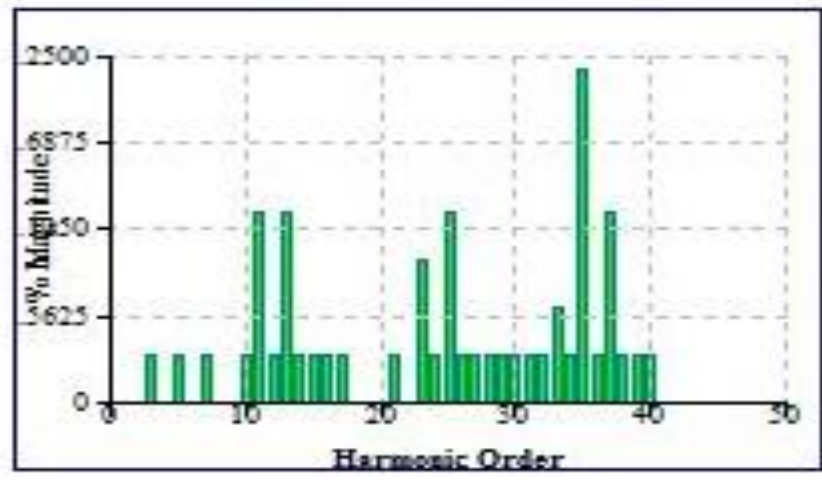

Fig. 4. Harmonics Voltage Source Model(Spectrum) of Abuja Steel Feeder

Table 2.Vihd Showing The Penetration Of $3^{\text {rd }}$ And $5^{\text {th }}$ Harmonics On The Network Using The Voltage Source Model

\begin{tabular}{lcc}
\hline Bus ID & VIHD & Harmonic Order \\
\hline Feld Base 11kV & 15.95 & 3.00 \\
Jere 11kV Bus & 14.15 & 3.00 \\
Jere 11kV Bus 1 & 13.95 & 3.00 \\
Suleja Main Bus & 13.34 & 3.00 \\
Suleja Transfer bus & 13.34 & 3.00 \\
Bus4 & 5.12 & 3.00 \\
Abuja Steel Bus1 & 5.99 & 5.00 \\
Feld Base 11kV & 2.82 & 5.00 \\
FieldBase 33kV Inj S/S & 4.88 & 5.00 \\
Jere 11kV Bus 1 & 2.51 & 5.00 \\
Jere 33kV Inj. S/S & 6.15 & 5.00 \\
Kantoma 11kV Bus 1 & 7.40 & 5.00 \\
Kantoma 11kV Bus 2 & 7.40 & 5.00 \\
Kantoma 33kV Inj. S/S & 7.55 & 5.00 \\
Suleja 11kV Bus & 6.39 & 5.00 \\
Suleja 33kV Bus 1 & 7.59 & 5.00 \\
Suleja 33kV Bus3 & 5.99 & 5.00 \\
Suleja Main Bus & 2.83 & 5.00 \\
Suleja Transfer Bus & 2.83 & 5.00 \\
\hline
\end{tabular}




\subsection{Comparison Of The Current And Voltage Source Models}

Preliminary analysis of the measured data for the current and voltage harmonics unbalance on the feeder reveals that the level of distortion from the current source model is higher than the voltage source model both in terms of relative magnitudes and phase angles. However, after simulation and harmonics analysis on the network, the total harmonic distortion of voltage (VTHD) was found to be similar irrespective of the model deployed. Therefore, it could be inferred that the two models reflect a proper harmonics model of the feeder and any of the two could be used.

\section{CONCLUSIONS}

In this work, the $33 \mathrm{kV}$ Abuja Steel Feeder was modeled as current and voltage harmonic source from measured data.

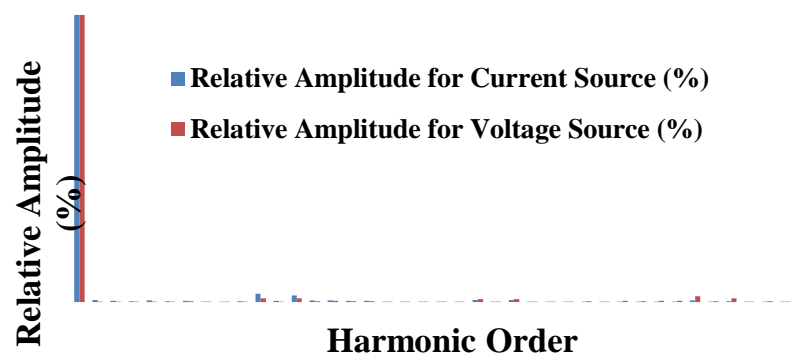

Fig. 5. Comparison of Relative Amplitude of Current and Voltage Harmonic Sources model for Abuja Steel - Current Source (deg)

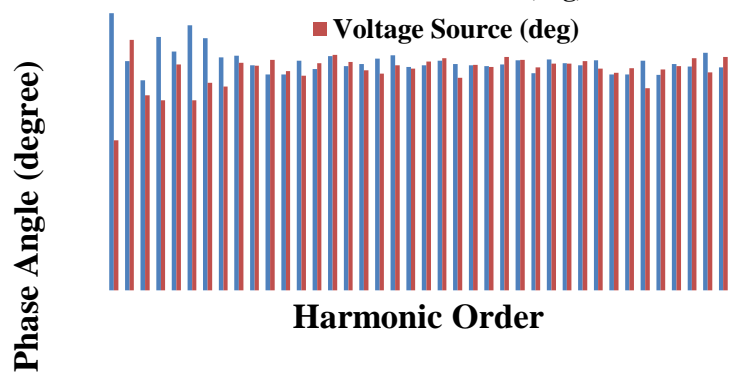

Fig. 6. Comparison of Phase Angles of Current and Voltage Harmonic Sources model for Abuja Steel. - VTHD from Current Source Model - VTHD from Voltage Source Model

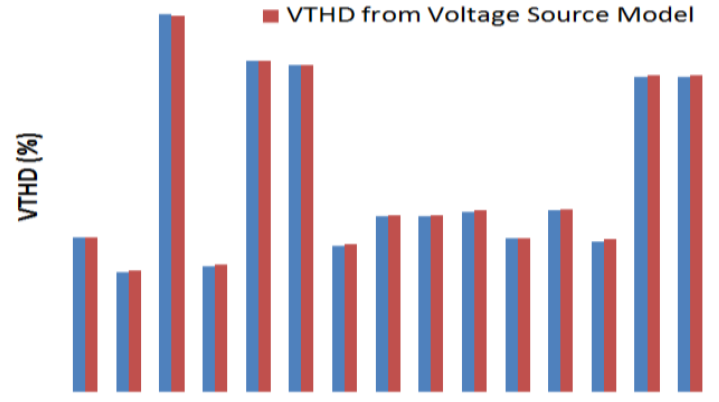

Fig. 7. Comparison of VTHD from Harmonics Analysis using Current Source Model and voltage Source Models of the Abuja steel feeder.
Readings were taken using PQube power quality analyzer to present the trend and harmonics unbalance on the feeder. The meter measures for each phase current and voltage harmonics amplitude, phase angle and inter-harmonics in a step-wise manner of 10 minutes. These data were further resolved to give resultant values per count. Daily average values were then populated for fundamental harmonics up to the $40^{\text {th }}$ order for further analysis using DFT. ETAP software package was deployed to perform DFT while the input parameters were the resultant relative amplitudes and phase angles for current and voltage source models. The current spectrum and voltage spectrum reveal that only the $3^{\text {rd }}$ and $5^{\text {th }}$ order harmonics threaten the power network as all the other higher orders cancelled out after analysis. However, the current and voltage source waveforms show high level of distorted sinusoidal waveforms.

\section{REFERENCES}

[1] Holey, D. M., Chandrakar, V. K. "Harmonic Analysis Techniques of Power Systems - A Review",International Research Journal of Engineering and Technology, pp. 680-684, 2016.

[2] Almeida,C. F., Kagan, N. "A Novel Technique for Modelling Aggregated Harmonic Producing Loads",21st International Conference on Electricity Distribution, p. 1217, Frankfurt, 2011.

[3] Amoo, A. L., Said, D. M., Said, Y. M., Zin, A. M. "Harmonic Power System in Nigerian Power Network with $\mathrm{PV}$ Site", IEEE,7th International Power Engineering and Optimization Conference, Langkawi, Malaysia, 2013

[4] Adesina L. M. and Fakolujo O.A. "Harmonic Analysis in a 33kV Distribution Network: A Case Study of Island Business District", African Journal of Computing \& ICT, 8:2, pp. 183-192, 2015.

[5] Saheed, L. G., Adegoke, M. "Effects of Steel Plants with Three Phase Induction Furnaces on Power Distribution Quality of the Existing $33 \mathrm{kV}$ Network in Nigeria",Advances in Science and Technology Research Journal, pp. 1-10,2015.

[6] Robert, G. E. Power System Harmonics: A Reference Guide to Causes, Effects and Corrective Measures, Allen-Bradley, 2001.

[7] Mekhamer, S. F., Abdelaziz, Y. M., Ismael, A. M. “Design Practices in Harmonic Analysis Studies Applied to Industrial Electrical Power System",Engineering Technology and Applied Science Research, pp. 467472, 2013.

[8] Roger, C. G., Mark, F. M., Surya, S., Wayne, H. B. Electrical Power Systems Quality, McGraw-Hill, 2004. 
[9] Khaled, M. E., Hanafy, M. I., Al-Fahd, M. "Harmonic Modelling, Analysis and Mitigation of Kuwait EHV Electrical Network",IEEE Electrical Engineering, pp.145-152, 2009.

[10]Ali, S. A. "Modeling of power networks by ATP-Draw for harmonics propagation studies", Transactions on Electrical and Electronics Materials, pp. 283-290, 2013.

[11]Hagh, M. T., Milani, A. R., Azimizadeh, M. R.. "Investigation of Harmonic Current Source Effect on Distribution and Transmission Line Capacity and Losses: Case Study",International Journal on Technical and Physical Problems of Engineering (IJTPE), pp. 81-85, 2011.

[12]Venkatesh, C., Kumar D. S., Sarma, S., Sydulu, M. "Modelling of Nonlinear Loads and Estimation of Harmonics in Industrial Distribution System",Fifteenth National Power Systems Conference (NPSC), pp. 592-597, Bombay, 2008.

[13] Ma, Z., You, G., \& Xu, Z. "Harmonic evaluation of grid with multiple harmonic sources based on DIgSILENT",International Conference on Power System Technology, pp. 2332 - 2337, 2014.
[14] Gül, Ö. and Gündoğdu, T. "Harmonic Contributions of Utility and Customer Based on Load Model Using Field Measurements",Journal of Power and Energy Engineering, 3, pp. 11-28, 2015.

[15] Bilandžija, D., Barukčić, M., Ćorluka, V. "Using an Evolutionary Algorithm for Harmonic Load Modeling by Norton and Thevenin Equivalents", International Journal of Electrical and Computer Engineering Systems, pp. 39-45, 2014.

[16] Ünverdi, E., Yildiz, A. B. “Equivalent Circuit Model Containing AC and DC Side Harmonics of Rectifier Circuits", 4th International Conference on Power Engineering, Energy and Electrical Drives,Istanbul, pp. 582-586, 2013.

[17] The Grid Code for the Nigerian Electricity Transmission System. - Version 01.2005

[18] IEC 61000-3-6: Assessment of emission limits for distorting loads in MV and HV power systems technical report part 3. 1996.

[19]IEEE Std. 519: Recommended Practices and Requirements for Harmonic Control in Electric Power Systems, 1992.

\section{APPENDIX: SINGLE LINE DRAWING OF THE SULEJA POWER NETWORK}

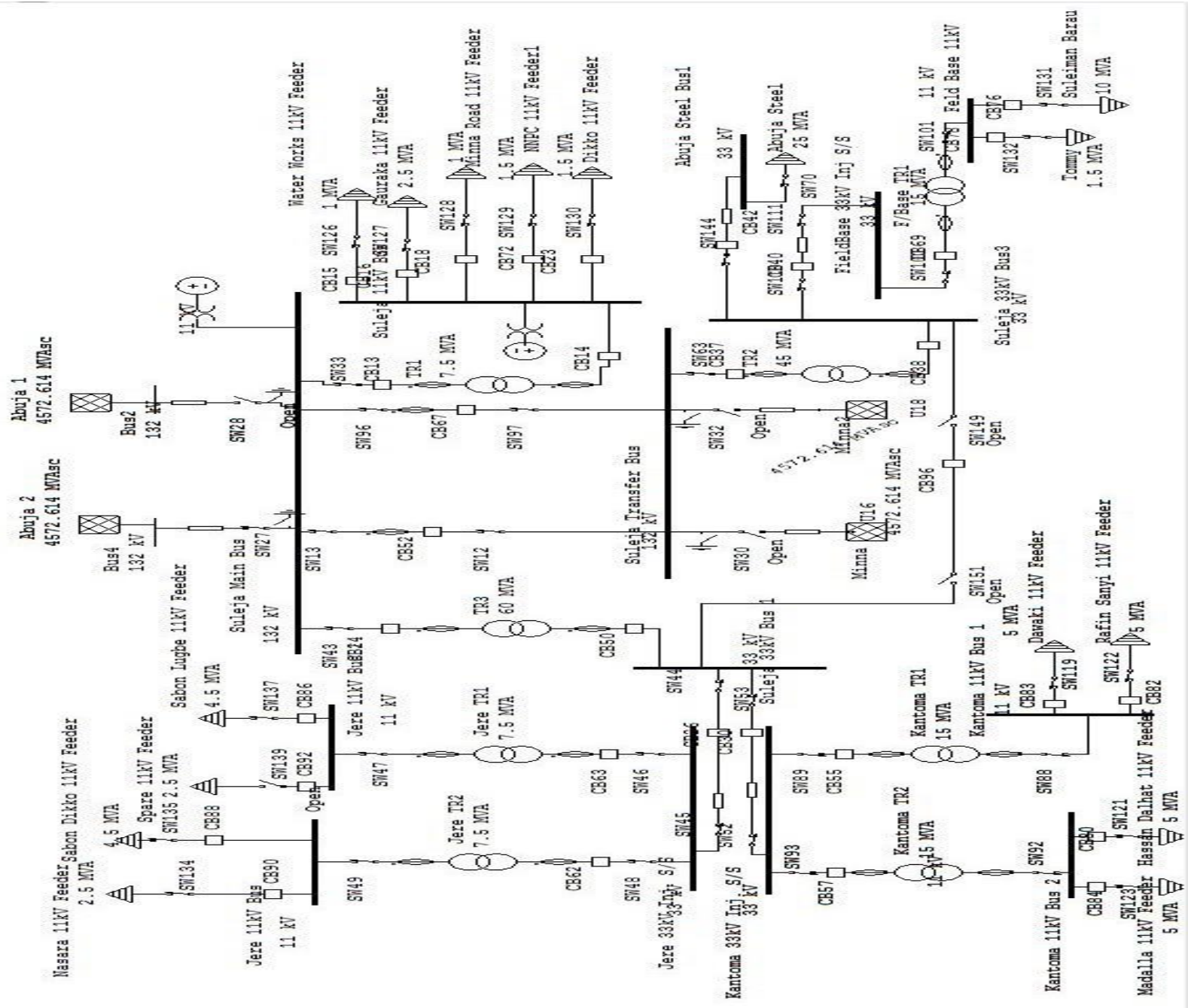

